\title{
Capsule Commentary on Nishizaki et al., Awareness of Diagnostic Error Among Japanese Residents: A Nationwide Study
}

\author{
Akira Kuriyama, $\mathrm{MD}, \mathrm{MPH}^{1,2}$ \\ 'Department of General Medicine, Kurashiki Central Hospital, Okayama, Japan; ${ }^{2}$ Emergency and Critical Care Center, Kurashiki Central Hospital, \\ Okayama, Japan.
}

$\mathrm{J}$ Gen Intern Med 33(4):494

DOI: $10.1007 / \mathrm{s} 11606-017-4270-0$

(c) Society of General Internal Medicine 2017

$\mathrm{D}$ ifferent nations have distinct and unique postgraduate clinical training programs. Currently, Japanese residents are required to rotate through three departments (internal medicine, emergency department [ED], and community medicine) and electively through other departments during a 2year residency after medical school (which in Japan is for 6 years after finishing high school).

This nationwide cross-sectional study ${ }^{1}$ assesses knowledge regarding diagnostic error (using the Diagnostic Error Knowledge Test; D-KAT) ${ }^{2}$ and clinical knowledge (using the General Medicine In-Training Examination; GM-ITE) among Japanese residents. ${ }^{3}$ Nishizaki et al. found that knowledge of diagnostic error was poorer among Japanese residents than their US counterparts, possibly because of the limited exposure to and lack of emphasis on clinical reasoning throughout graduate and postgraduate medical education, as the authors postulate.

Using structural equation modeling, the authors were able to tease out potential causative factors for D-KAT scores. These scores were directly associated with GIM-ITE scores, and indirectly with a greater number of ED rotations, increased inpatient caseload, and more time spent on self-study. Greater opportunities for clinical experience and self-study may thus enhance clinical and diagnostic skills.

"Work harder, study harder, and you will become an improved diagnostician" may seem intuitively correct, but this study suggests that too little or too much of either may reduce performance quality. US residents are limited to an 80-h work weekly by the Accreditation Council for Graduate Medical
Education. ${ }^{4}$ In Japan, there is no specific rule; while the Labor Standards Act restricts working hours to 40 per week equally for all workers in Japan, undocumented overtime work by Japanese residents is a common problem. Also, unlike the US, Japan has no inpatient caseload limit. The specific caseload and number of hours varies widely among hospitals and even among attending physicians. The study by Nishizaki et al. points out that a higher caseload can have a detrimental effect on resident knowledge acquisition. Determining the "sweet spot" of an appropriate workload, one that affords residents the time both for reflection on their own clinical practice and for self-study, is important. Reform efforts are needed to set such limits for Japanese postgraduate clinical training programs.

Corresponding Author: Akira Kuriyama, MD, MPH; Department of General Medicine, Kurashiki Central Hospital, Okayama, Japan (e-mail: akira.kuriyama.jpn@gmail.com).

Compliance with Ethical Standards:

Conflict of Interest: The author has no conflicts of interest with this article.

\section{REFERENCES}

1. Nishizaki Y, Shinozaki T, Kinoshita K, Shimizu T, Tokuda Y. Awareness of Diagnostic Error among Japanese Residents: A Nationwide Study. J Gen Intern Med. doi:https://doi.org/10.1007/s11606-017-4248-y.

2. Reilly JB, Ogdie AR, Von Feldt JM, et al. Teaching about how doctors think: a longitudinal curriculum in cognitive bias and diagnostic error for residents. BMJ Qual Saf. 2013;22(12):1044-50.

3. Shimizu T, Tsugawa $\mathbf{Y}$, Tanoue $\mathbf{Y}$, et al. The hospital educational environment and performance of residents in the General Medicine InTraining Examination: a multicenter study in Japan. Int $\mathrm{J}$ Gen Med. 2013;6:637-40.

4. Nasca TJ, Day SH, Amis ES Jr, for the ACGME Duty Hour Task Force. The new recommendations on duty hours from the ACGME Task Force. N Engl J Med. 2010;363(2):e3. 